\title{
Do laboratory animals have rights?
}

\section{The months ahead threaten more wrangling about the status of laboratory animals. The long-promised European Convention could be a useful framework.}

THE problem of laboratory animals, always with us, is likely to become more obvious in the months ahead as the Council of Europe nears the end of its attempt to negotiate an acceptable international convention on the subject (see page 284) and as the body of opinion that calls itself the animal liberation movement gathers strength, as seems likely. In Britain, the issue was made more pointed last week when Professor Peter Singer of the Australian National University delivered a television lecture as part of a kind of celebration of the British Broadcasting Corporation's "Horizon" programmes (often rebroadcast as part of the Nova series in the United States). Singer, a philosopher by trade, has won a reputation among those who break into laboratories and steal the animals they find there, and now in Britain send letter bombs through the post, as the man who makes their vandalism respectable - an allegiance that Singer himself refuses.

Singer's argument is interesting and provocative, and deserves attention even by those who disagree with it, or with its conclusions. The argument has three components. First, Singer says, the notion that animals may properly be used as human beings calculate will best serve human interests is akin to older notions that barbarians or aboriginals could be killed (or made into slaves) on the grounds that they were lesser beings, and is just as ethically improper. "Speciesism" is Singer's word. Second, to justify the mistreatment of animals on the grounds that interspecific competition is unavoidable in evolutionary terms is unjustifiable and at odds with moral progress (if not practice) in recent years. Third, it does not however follow that all animal species are equal, but rather that in the design of experiments in which animals are used, those responsible should put themselves in the animal's shoes, asking themselves how they would welcome what is planned, in which case (Singer rightly says) a relevant consideration is that as much as possible should be learned by observation of the behaviour of the nonhuman species so as to estimate its capacity for suffering.

The argument is consistent enough. It does not of course imply that animal experiments cannot be carried out, but merely that there would be fewer of them. Singer, fair play, reinforces his conclusion with several provocative examples. Thus on the speciesism question, if the line is drawn between those with developed mental faculties and those without, why not use newborn children rather than dogs? Why not in any case use brain-dead people as experimental animals? And if chimpanzees are the only animal models of hepatitis B infection, but are an endangered species, why not ask for human volunteers instead?

Less radical arguments leading to very similar conclusions are also, of course, familiar. Thus even within the framework of what Singer calls speciesism, it is possible to argue that the practice of cruelty to animals debases human beings and runs the risk that familiarity with animal cruelty will engender cruelty to people. More to the point, wantonly to cause pain to animals is painful for those who witness these procedures, who learn about them or suspect that they may be going on. For what the animal liberation movement does not appreciate or accept is that even those who work in laboratories with laboratory animals find many of the procedures personally painful.

Largely on such grounds, most governments have now found it necessary to regulate the use of experimental animals by legislation. In the standard model, those who use laboratory animals must be registered, even licensed, and there are usually regulations requiring that animals should not be operated on without anaesthetics, that animal experiments should not be carried out in public and that animals should not be allowed to recover from damaging operations but should be killed instead. Needless pain is to be avoided. And then there are usually procedures by which exceptions to these rules may be permitted. The practical position, in other words, is not very different from Singer's.

So why not aim at legislation that will represent a reasonable compromise between the animal liberation movement and laboratory scientists, persuading both groups that since their chief objectives will be satisfied by the draft of the European Convention now circulating, there is no reason why they should not settle for an agreed prescription? For laboratory scientists, there are three snags: the convention would (and should) cover animals used for the routine production of antisera, would require that laboratory animals should always be bred especially for the purpose intended and is imprecise about the circumstances in which exception from the strict rules will be allowed (and by whom). But should that hold up the signature of the European Convention, now so long put off that its non-existence must be offensive to those who want something done?

The danger is that further delay will play into the hands of people like Mr Singer. Singer's implied assertion that there is no sharp line to be drawn between people and other species of animals overlooks several simple truths. Populations of domesticated animals are controlled both as to number and to kind by people, not by the species concerned. While there may be no immediate interspecific conflict between people and other species now that smallpox has been eradicated, and although a practical way of eliminating Anopheles mosquitos would probably still be welcomed even though there is a vaccine round the corner, who can be sure that the survival of people this far has not been made possible by past interspecific conflicts? And is it, in any case, possible to think that the modern medicines for which the developed world is clamouring can be developed safely on the basis of clinical trials rather than with laboratory tests with animals? People might volunteer to be subjects in a trial of hepatitis $B$ vaccines out of ignorance, but would hardly rush to help test the efficacy of some new analgesic.

The animal liberation movement is, for these reasons, doomed to failure but certain to cause trouble in the meantime. The scientific community would do well to answer positively, and not simply by means of the familiar case for research with laboratory animals that usually there is no alternative method.

Why not, instead, answer Singer's paradoxes with others? If the safety of some new medicine has not been assured by laboratory tests with animals, why noî invite human volunteers and pay them a fee for their time and trouble? (It is not so long since the practice of offering prisoners in gaol a respite from their sentences was stopped by public demand, and rightly.) Or why should not the manufacturers of some promising new drug be allowed to advertise in the newspapers for those likely to benefit who are also prepared to take the drug untested? The answer to both questions is that governments, societies and people would not allow such things to happen. $\mathrm{Mr}$ Singer would no doubt complain of a resurgence of speciesism, but to no effect. 